\title{
Characterization of the Resistance Mechanism and Risk of Fusarium verticillioides to the Myosin Inhibitor Phenamacril
}

\author{
Weichao Ren, ${ }^{1,2} \mathrm{Na}$ Liu, ${ }^{2}$ Yiping Hou, ${ }^{1}$ Baohua Li, ${ }^{2}$ Mingguo Zhou, ${ }^{1}$ and Changjun Chen ${ }^{1, \dagger}$ \\ ${ }^{1}$ College of Plant Protection, Nanjing Agricultural University, Nanjing, Jiangsu, China \\ ${ }^{2}$ College of Plant Health and Medicine, Qingdao Agricultural University, Qingdao, Shandong, China \\ Accepted for publication 17 January 2020.
}

\begin{abstract}
Fusarium verticillioides is a major pathogen of maize that causes ear rot and produces mycotoxins. Phenamacril is a novel cyanoacrylate fungicide that exhibits favorable activity against Fusarium species. In this study, the phenamacril-resistant mutants of $F$. verticillioides were obtained by ultraviolet mutagenesis. Single point mutations of S73L or E276K in the myosin-1 FvMyo1 were proven to be responsible for the high-level resistance of $F$. verticillioides to phenamacril. Phenamacril had a significant impact on the localization of the wild-type FvMyo1

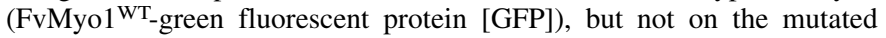

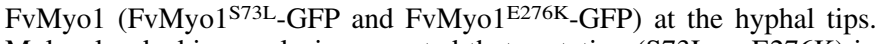
Molecular docking analysis suggested that mutation (S73L or E276K) in FvMyo1 altered the binding mode and decreased the binding affinity between phenamacril and myosin-1. There was no significant fitness penalty in mycelial growth, conidiation, and virulence of $F$. verticillioides associated with resistance to phenamacril. The results will enhance our understanding of the resistance mechanism of $F$. verticillioides to phenamacril and provide new reference data for the management of maize ear rot.
\end{abstract}

Maize (Zea mays L.), also known as corn, is one of the most important crops in the world and has a wide variety of uses, including food, feed, and industrial material (Ranum et al. 2014). Fusarium verticillioides (teleomorph Gibberella moniliformis) is one of the most common pathogens of maize that causes ear and stalk rot of maize worldwide (Munkvold 2003). In addition to high yield losses, $F$. verticillioides can also synthesize mycotoxins (most notably, fumonisins) in infested corn (Rheeder et al. 2002; Seo et al. 2001). The structure of fumonisins is similar to that of sphinganine and they disrupt sphingolipid metabolism by inhibiting ceramide synthase (Nelson et al. 1993). Elevated levels of fumonisins in naturally contaminated corn have been associated with high incidences of several animal diseases as well as cancer in humans (Fink-Grernmels 1999; Norred and Voss 1994). Despite its enormous negative impact on corn production, $F$. verticillioides is not adequately controlled with currently available commercial fungicides, resistant maize cultivars, or cultural practices. Therefore, the development of research-supported effective control measures is urgently needed.

The cyanoacrylate fungicide phenamacril (experimental code JS399-19; active ingredient: 2-cyano-3-amino-3-phenylancryic acetate), developed by the Jiangsu Branch of the National Pesticide Research and Development Center of China, is a Fusarium-specific fungicide (Li et al. 2008). In China, phenamacril has been registered for controlling wheat head blight (WHB) and rice bakanae caused by F. graminearum and F. fujikuroi, respectively, since 2012 (Hou et al. 2018). Phenamacril exhibits satisfactory control efficiency and

†Corresponding author: C. Chen; changjun-chen@njau.edu.cn

Funding: This work was supported by grants from the National Natural Science Foundation of China (31672065), the National Key R\&D Program of China (2016YED0201007, 2018YFD0201201, and 2018YFD0201000), and the Agricultural Projects of Jiangsu Province, China (BE2018378, PZCZ201715, BA2018039, and CX(18)2005).

*The $\boldsymbol{e}$-Xtra logo stands for "electronic extra" and indicates that one supplementary table is published online.

The author(s) declare no conflict of interest.

C 2020 The American Phytopathological Society deoxynivalenol (DON) suppression for WHB in the field (Tang et al. 2018). For many years, phenamacril-resistant (PR) strains of $F$. fujikuroi and F. graminearum were not found in the field. However, resistant strains of $F$. fujikuroi were isolated from a rice field in Zhejiang Province in 2016 (Hou et al. 2018). Previous studies showed that phenamacril showed moderate to high resistance risk for controlling $F$. graminearum, $F$. fujikuroi, and $F$. oxysporum f. sp. melonis (Hou et al. 2018; Li et al. 2016; Zhang et al. 2018). Previous studies showed that the class I myosin-5 was the target of phenamacril and mutations in myosin-5 conferred resistance to the fungicide in F. graminearum, F. fujikuroi, and F. oxysporum f. sp. melonis (Hou et al. 2018; Zhang et al. 2015, 2018; Zheng et al. 2015). In addition, myosin-5 interacts with Tri1 and actin and participates in DONtoxisome formation in F. graminearum (Tang et al. 2018).

Given its good efficacy on Fusarium species, phenamacril is considered as a potential alternative to control $F$. verticillioides. Yet the biology of phenamacril resistance in $F$. verticillioides is still unknown. In this study, the molecular basis of $F$. verticillioides to phenamacril was characterized, and the resistance risk was preliminarily assessed.

\section{MATERIALS AND METHODS}

Strains, media, and fungicides. $F$. verticillioides strain 7600 (FGSC7600) was used as the parental strain for phenamacrilresistance mutagenesis. Potato dextrose agar (PDA; $200 \mathrm{~g}$ of potato, $20 \mathrm{~g}$ of glucose, $15 \mathrm{~g}$ of agar, and 1 liter of water) was used for mycelial growth and colony maintenance. Carboxymethyl cellulose $\left(\mathrm{CMC} ; 1 \mathrm{~g}\right.$ of $\mathrm{NH}_{4} \mathrm{NO}_{3}, 1 \mathrm{~g}$ of $\mathrm{KH}_{2} \mathrm{PO}_{3}, 0.5 \mathrm{~g}$ of $\mathrm{MgSO}_{4} \cdot 7 \mathrm{H}_{2} \mathrm{O}, 1 \mathrm{~g}$ of yeast extract, $15 \mathrm{~g}$ of carboxymethylcellulose, and 1 liter of water) was used for conidiation. Phenamacril (95\% active ingredient) was provided by Jiangsu Pesticide Research Institute Co., Ltd. and dissolved in dimethylsulfoxide to make a stock solution (10 $\mathrm{mg} \mathrm{ml}^{-1}$ ). Tebuconazole $(97 \%)$ was provided by Jiangsu Pesticide Research Institute Co., Ltd. and dissolved in methanol to make a stock solution $\left(10 \mathrm{mg} \mathrm{ml}^{-1}\right)$. Carbendazim (98\%) was provided by Jiangsu Lanfeng Biochemical Limited Co., Ltd. and dissolved in $0.1 \mathrm{M}$ of hydrochloric acid to make a stock solution $\left(10 \mathrm{mg} \mathrm{ml}^{-1}\right)$. 
Generation of PR mutants. To obtain PR mutants, $1 \times 10^{6}$ conidia of strain 7600 were spread onto PDA plates supplemented with $100 \mu \mathrm{g} \mathrm{ml}^{-1}$ of phenamacril and exposed to ultraviolet (UV) light for $90 \mathrm{~s}$. After UV radiation, the plates were incubated at $25^{\circ} \mathrm{C}$ for 7 days, and the PR colonies growing on the plates were obtained. A total of 12 independent single-spore PR colonies were isolated for FvMYO1 sequence analysis.

Cloning and sequence analysis of FvMYO1. Genomic DNA of $F$. verticillioides was extracted using the conventional cetyltrimethylammonium bromide method (Möller et al. 1992). Based on the fungal genome database (https://fungidb.org/fungidb/), the open reading frames (ORFs) of myosin-1 gene $F v M Y O 1$ were amplified from the sensitive and resistant strains with the primer pair P1/P2 (Supplementary Table S1). The resultant PCR products were sequenced directly, and the sequences were aligned with BioEdit software.

Construction of the FvMyo1-GFP fusion cassette and microscopy. To observe the localization of FvMyo1 in $F$. verticillioides, the FvMYO1 gene ORF including the native promoter region was fused with carboxy-terminal green fluorescent protein (GFP) and transformed into wild-type (WT) strain 7600 by the polyethylene glycol-mediated method as described previously (Shim and Woloshuk 2001). FvMyo1-GFP fluorescence signals in fresh hyphae of each strain harvested from yeast extract peptone dextrose medium amended with or without $2 \mu \mathrm{g} \mathrm{ml} \mathrm{m}^{-1}$ of phenamacril were examined with the Zeiss LSM780 confocal microscope (Carl Zeiss AG, Jena, Germany).

Sensitivity test to different fungicides. For the mycelial sensitivity assays, mycelial plugs were placed on PDA plates amended with phenamacril at $0,0.5,1,2,4$, and $8 \mu \mathrm{g} \mathrm{ml}^{-1}$ or at 0,25 , $50,100,200$, and $400 \mu \mathrm{g} \mathrm{ml}^{-1}$, with carbendazim at $0,0.1,0.2,0.4$, 0.8 , and $1.6 \mu \mathrm{g} \mathrm{ml}^{-1}$, and with tebuconazole at $0,0.01,0.02,0.04$, 0.08 , and $0.16 \mu \mathrm{g} \mathrm{ml}^{-1}$. After cultures were kept at $25^{\circ} \mathrm{C}$ for 4 days, the radial growth on each plate was measured perpendicularly and averaged to calculate the percentage of growth inhibition. For the conidial sensitivity assays, $5-\mu l$ conidia suspensions $\left(1 \times 10^{5} \mathrm{ml}^{-1}\right)$ of each strain were incubated on 12-well plates containing PDA with phenamacril at $0,1,510,50,100,200$, and $400 \mu \mathrm{g} \mathrm{ml}^{-1}$. Photographs were taken after incubation at $25^{\circ} \mathrm{C}$ for 2 days. The effective concentration for $50 \%$ inhibition of mycelial growth $\left(\mathrm{EC}_{50}\right)$ was calculated by the regression of the probit of the percentage of inhibition of radial growth against the logarithmic value of phenamacril concentration. The experiments were performed three times independently.

Determination of biological fitness. To determine the mycelial growth rate, the PR mutants (transformed mutants and UV mutants) and corresponding parental strain were placed on PDA plates. After incubation at $25^{\circ} \mathrm{C}$ for 4 days, the colony diameters were measured perpendicularly and averaged. There were three replicates in each test and the experiment was repeated three times independently.

To determine conidiation, an equal amount of mycelia from each strain was cultured in an equal volume of CMC medium. After incubation at $25^{\circ} \mathrm{C}$ for 4 days in a shaker $(180 \mathrm{rpm})$, conidia were quantified with a hemocytometer. The experiment was repeated three times independently.

To determine virulence, conidia of each strain were collected and adjusted to a concentration of $1 \times 10^{6}$ conidia $\mathrm{ml}^{-1}$. Ten microliters of conidial suspension was used to inoculate maize stalks via a hole punched in the stem. The control maize stalks were inoculated with $10 \mu \mathrm{l}$ of sterilized water. Each strain was represented by 10 replicates. After inoculation, the maize stalks were maintained at $25 \pm 2^{\circ} \mathrm{C}$ under $80 \%$ relative humidity and a $12-\mathrm{h} / 12$-h light/dark cycle. After 15 days, the disease lesion sizes on maize stalks were measured and averaged. The experiment was repeated four times independently. Data analysis was carried out with SPSS 20 software (IBM). Significance tests adopted least significant difference and Duncan methods. Error bars in the figures represent the standard deviations from three independent experiments and values on the bars followed by the same letter are not significantly different at $P=0.05$.

Molecular docking analysis. The protein sequence of FvMyo1 (XP_018756374.1) was obtained from the NCBI database. The three-dimensional structure of myosin-1 was built by the crystal structure of the human Mus musculus Myosin-V (Protein Data Bank identifier 2DFS) by using the SWISS-MODEL web server (Liu et al. 2006; Waterhouse et al. 2018). The binding mode of phenamacril in the binding site of myosin-1 was predicted by AutoDock (version 4.2.6) (Morris et al. 2009). The proteins and ligand were prepared by AutoDockTools software (version 1.5.6). A grid box size of $60 \times 60 \times 60$ dimensions, with a spacing of 0.375 $\AA$ between the grid points, was implemented and covered almost the entire actin binding cleft of myosin-1. The Lamarckian genetic algorithm (LGA) was utilized for globe conformational sampling. In the LGA runs, trials of 200 dockings and the number of energy evaluations were set to 2,500,000, and other settings were set as default. The lowest binding energy conformation was considered for further analysis.

\section{RESULTS}

Generation of $F$. verticillioides mutants resistant to phenamacril. A total of $12 \mathrm{PR}$ mutants were obtained by UV mutagenesis, selecting for strains that grew well on PDA plates amended with $100 \mu \mathrm{g} \mathrm{ml}^{-1}$ of phenamacril after 3 days of incubation. In contrast, WT strain 7600 failed to grow even at $15 \mu \mathrm{g} \mathrm{ml}^{-1}$.

Myosin-1 gene sequence analysis in PR mutants. The myosin-1 gene FvMYO1 (FVEG_09486) (Fig. 1A) from all PR mutants was sequenced and aligned with $F v M Y O 1$ of WT strain 7600. The PR mutants contained two types of single point mutation in FvMYOl, designated as PR-I and PR-II. For PR-I mutants, codon 175 (TCA) for serine was changed to a codon (TTA) for leucine. For PR-II mutants, codon276 (GAG) for glutamic acid was changed to a codon (AAG) for lysine (Fig. 1B). Both of the mutation sites were located in the motor domain of myosin-1.

Mutation in myosin-1 confers resistance of $F$. verticillioides to phenamacril. To verify whether the resistance of $F$. verticillioides to phenamacril is caused by a point mutation (S73L or E276K) in FvMyo1, the constructs encoding the WT (without mutations) or individual-point mutated (C218T or G826A) FvMYO1 were introduced into WT strain 7600, resulting in strains FvMyo1 ${ }^{\mathrm{WT}}$, FvMyo1 $^{\mathrm{S} 73 \mathrm{~L}}$, and FvMyo1 ${ }^{\mathrm{E} 276 \mathrm{~K}}$, respectively. As shown in Figure 2, both FvMyo1 ${ }^{\text {S73L }}$ and FvMyo1 ${ }^{\text {E276K }}$ strains exhibited lower sensitivity to phenamacril and were able to grow on PDA plates amended with $400 \mu \mathrm{g} \mathrm{ml}^{-1}$ of phenamacril, which was consistent with the PR mutants (PR-I and PR-II), whereas FvMyo1 ${ }^{\mathrm{WT}}$ remained sensitive to phenamacril and failed to grow even at $30 \mu \mathrm{g} \mathrm{ml}^{-1}$. In addition, similar results were observed in the conidial sensitivity assays (Fig. 3). Notably, mutations in myosin-1 did not cause significant changes in

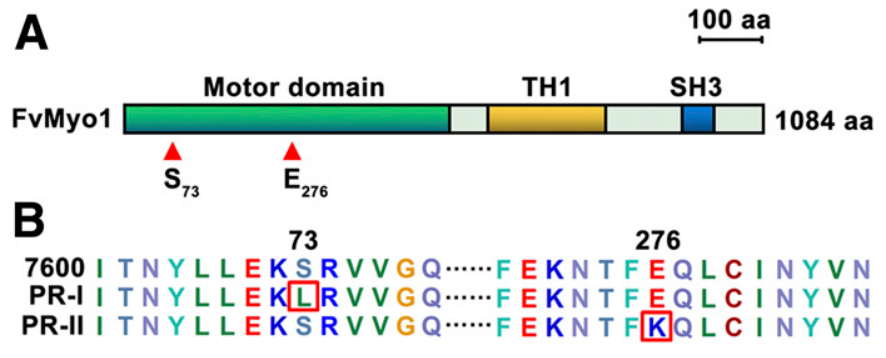

Fig. 1. Structure and sites of the mutation in myosin-1 associated with phenamacril resistance in Fusarium verticillioides. A, Structure of the FvMyol protein. The conserved motor domain, myosin tail homology 1 (TH1), and Src homology domain 3 (SH3) are highlighted. The mutation sites Ser73 and Glu276 are indicated with triangles. Bar represents 100 amino acids (aa). B, Alignment of partial amino acid sequences of FvMyo1 from the parental strain 7600 and the phenamacril-resistant (PR) mutants PR-I and PR-II. The amino acid changes in phenamacril-resistant mutants are indicated with boxes. 
sensitivity toward other fungicides with different modes of action, such as carbendazim and tebuconazole (Table 1). Collectively, these results suggested that point mutations S73L or E276K in FvMyo1 conferred specific resistance to phenamacril in F. verticillioides.

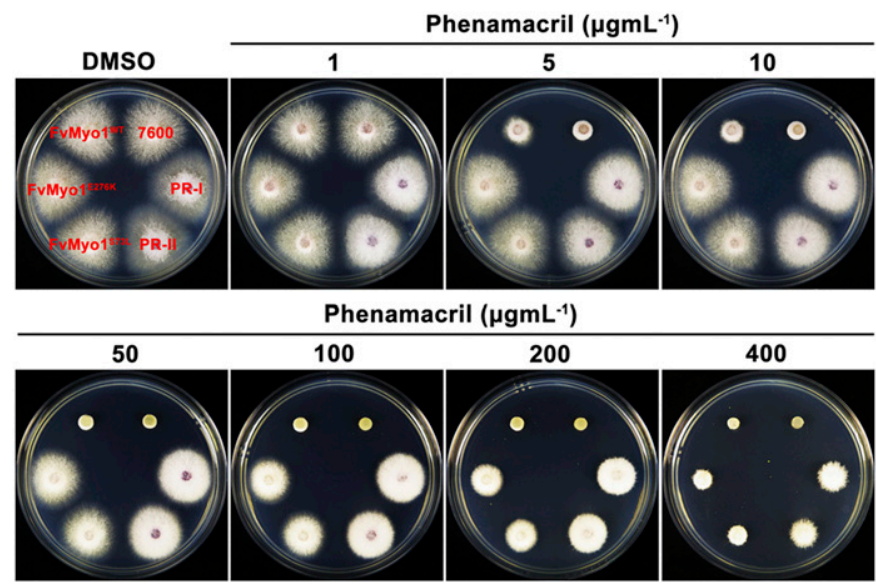

Fig. 2. Mycelial growth of Fusarium verticillioides strains on potato dextrose agar (PDA) plates amended with phenamacril. The parental strain 7600, the laboratory-induced phenamacril-resistant (PR) mutants PR-I and PR-II, the artificially constructed strains FvMyo1 ${ }^{\mathrm{S} 73 \mathrm{~L}}$ (7600 transformed with the mutated FvMYO1 containing the point mutation S73L), FvMyo1 ${ }^{\mathrm{E} 276 \mathrm{~K}}(7600$ transformed with the mutated $F v M Y O 1$ containing the point mutation E276K), and FvMyo $1^{\text {WT }}$ (7600 transformed with the wild-type FvMYO1) were grown on PDA plates amended with serial concentrations of phenamacril for 2 days at $25^{\circ} \mathrm{C}$. DMSO $=$ dimethylsulfoxide

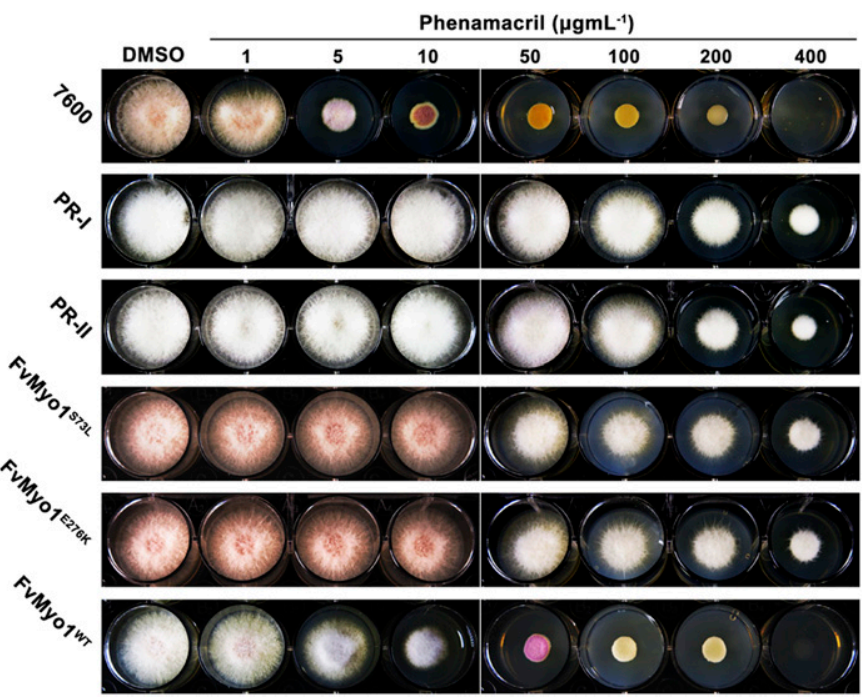

Fig. 3. Conidial germination of Fusarium verticillioides strains on potato dextrose agar (PDA) plates amended with phenamacril. Conidia of each strain were cultured on PDA plates amended with serial concentrations of phenamacril for 2 days at $25^{\circ} \mathrm{C}$. DMSO = dimethylsulfoxide. $\mathrm{PR}=$ phenamacril resistant and $\mathrm{WT}=$ wild type.
Subcellular localization analysis of FvMyo1-GFP. To explore the effect of phenamacril on FvMyo1 location in mycelium, the WT and mutated FvMYOI fused with GFP were transformed into WT strain 7600, respectively. Microscopic examination showed that strong

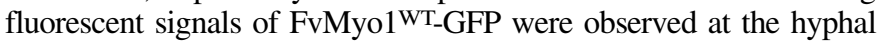
tips and diminished dramatically after the treatment with $2 \mu \mathrm{g} \mathrm{ml}^{-1}$ of phenamacril for $4 \mathrm{~h}$ (Fig. 4). However, the fluorescent signals at the hyphal tips of mutated proteins FvMyo1 ${ }^{\text {S73L-GFP and FvMyo1E276K_ }}$ GFP were not affected dramatically by phenamacril treatment (Fig. 4). These results indicated that mutation (S73L or E276K) in FvMyo1 can overcome the dislocation caused by phenamacril.

Analysis of binding affinity between myosin-1 and phenamacril. The interactions between myosin (WT/S73L/ E276K) and phenamacril were evaluated by molecular docking analysis. The docking results indicated that phenamacril formed four hydrogen bonds with the residues of Leu-70, Ser-73, and Lys393 in the WT myosin (Fig. 5A). However, phenamacril in S73L myosin exhibited a significant difference from the WT pattern that forms three hydrogen bonds with the residues of Gly-77, Ile-79, and Glu-276 (Fig. 5B). In addition, phenamacril in S73L myosin showed obvious movement out of the binding pocket, which may be attributable to the loss of the two important hydrogen bonds between phenamacril and Ser-73 that resulted in the instability of phenamacril in the binding site. As for the mutation of E276K, the increase in the amino acid length of Glu-276 to Lys-276 may hinder the binding of phenamacril to the active site (Fig. 5C).

Biological fitness analysis. To assess the fitness of PR mutants, mycelial growth rate, conidiation, and virulence were determined. Compared with WT strain 7600, the UV-induced resistant mutants showed a significant decrease in mycelial growth, conidiation, and virulence (Fig. 6; Table 2). However, the artificially constructed point mutation strains exhibited similar phenotypes to WT strain 7600 (Fig. 6; Table 2). These results indicated that there was no significant fitness penalty of $F$. verticillioides associated with resistance to phenamacril.

\section{DISCUSSION}

Phenamacril exhibits high antifungal activity against Fusarium species, and it has great potential for registration for controlling corn ear rot mainly caused by $F$. verticillioides. To date, there is no report on the biology of phenamacril against $F$. verticillioides. In this study, we investigated the resistance mechanism and assessed the resistance risk of $F$. verticillioides to phenamacril.

Like other Fusarium species, phenamacril displayed strongly inhibitory activity against mycelial growth and conidial germination of $F$. verticillioides. Considering that $F$. verticillioides can be seed transmitted and cause systemic maize infection (Wilke et al. 2007), phenamacril is likely to be developed as a seed coating formulation.

Previous studies showed that phenamacril resistance in $F$. graminearum was caused by a mutation in myosin-5 (Zhang et al. 2015; Zheng et al. 2015). For the laboratory-induced resistant mutants of $F$. graminearum, mutations at different sites resulted in different resistance levels, and the single point mutations A135T,

TABLE 1. Sensitivity ( $\left.\mathrm{EC}_{50} / \mathrm{MIC}\right)$ of Fusarium verticillioides strains to phenamacril, carbendazim, and tebuconazole ${ }^{\mathrm{z}}$

\begin{tabular}{|c|c|c|c|c|}
\hline \multirow[b]{2}{*}{ Strain } & \multicolumn{3}{|c|}{$\mathrm{EC}_{50}\left(\mu \mathrm{g} \mathrm{ml}^{-1}\right)$} & \multirow[b]{2}{*}{ Phenamacril MIC $\left(\mu \mathrm{g} \mathrm{ml}^{-1}\right)$} \\
\hline & Phenamacril & Carbendazim & Tebuconazole & \\
\hline 7600 & $2.18 \pm 0.17 \mathrm{a}$ & $0.42 \pm 0.057 \mathrm{a}$ & $0.027 \pm 0.0023 \mathrm{a}$ & $<15$ \\
\hline PR-I & $138.54 \pm 1.37 \mathrm{~d}$ & $0.42 \pm 0.059 \mathrm{a}$ & $0.029 \pm 0.0027 \mathrm{a}$ & $>800$ \\
\hline PR-II & $140.73 \pm 1.43 \mathrm{~d}$ & $0.43 \pm 0.071 \mathrm{a}$ & $0.030 \pm 0.0038 \mathrm{a}$ & $>800$ \\
\hline FvMyo $1^{\text {S73L }}$ & $115.69 \pm 1.29 \mathrm{c}$ & $0.41 \pm 0.048 \mathrm{a}$ & $0.029 \pm 0.0034 \mathrm{a}$ & $>800$ \\
\hline FvMyo $1^{\text {E276K }}$ & $117.35 \pm 1.33 \mathrm{c}$ & $0.42 \pm 0.062 \mathrm{a}$ & $0.028 \pm 0.0036 \mathrm{a}$ & $>800$ \\
\hline FvMyo ${ }^{\mathrm{WT}}$ & $13.41 \pm 0.86 \mathrm{~b}$ & $0.43 \pm 0.065 \mathrm{a}$ & $0.029 \pm 0.0041 \mathrm{a}$ & $<30$ \\
\hline
\end{tabular}

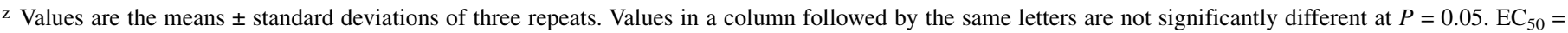
concentration causing $50 \%$ growth inhibition, MIC $=$ minimal inhibitory concentration, $\mathrm{PR}=$ phenamacril resistant, and WT $=$ wild type 
V151M, P204S, I434M, A577T, R580G/H, or I581F caused low resistance; the single point mutations S418R, I424R, and A577G caused moderate resistance; and the single point mutations K216R/E, S217P/L, and E420K/G/D caused high resistance (Li et al. 2016). In F. fujikuroi, only two types of point mutation, S219P/L, in myosin-5 were found in the field-resistant mutants (Hou et al. 2018). For the laboratory-induced resistant mutants of F. oxysporum f. sp. melonis, $\mathrm{S} 175 \mathrm{~L}$ may mediate resistance toward phenamacril (Zhang et al. 2018). Amino acid substitutions ( $\mathrm{Val}_{151}$ to Ala and $\mathrm{Ser}_{418}$ to $\mathrm{Thr}$ ) in the FoMyo5 motor domain led to natural resistance to phenamacril in F. oxysporum (Zheng et al. 2018). In this study, we obtained 12 PR strains by UV mutagenesis, which showed two types of mutations: S73L (83\%) and E276K (17\%). Both types of mutation conferred high-level resistance to phenamacril, which is consistent with the homologous loci mutation for phenamacril resistance in F. graminearum (Zhang et al. 2015; Zheng et al. 2015).

Proteins can only function properly if they are in the right location (Ćmielová and Rezáčová 2011). In this study, the subcellular localization of the WT FvMyol protein was affected dramatically by phenamacril, whereas the effects of phenamacril on the mutated FvMyo1 protein (S73L or E276K) were not significant. Thus, the inhibitory activity of phenamacril against $F$. verticillioides may be achieved by interfering myosin-1 distribution. In most cases, resistance is related to point mutations in the target gene, which resulted in changes of amino acid sequences at the fungicide binding site (Ma and Michailides 2005). In this study, the binding affinity between phenamacril and the WT FyMyo1 protein was significantly higher than that between phenamacril and the mutated FvMyo1 protein (S73L or E276K), which may be the main reason for the resistance of $F$. verticillioides to phenamacril.

The biological fitness of resistant mutants is an extremely important parameter regarding the risk for development of resistance (Hawkins and Fraaije 2018). For the laboratory-
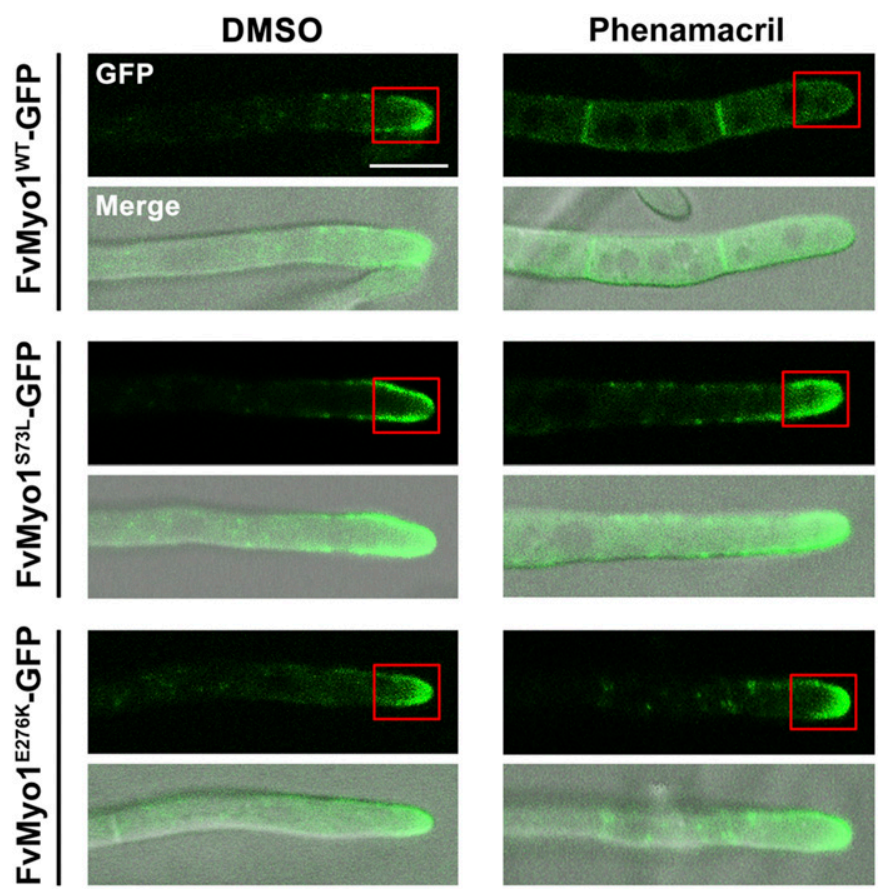

Fig. 4. Subcellular localization of FvMyo1 in Fusarium verticillioides. My-

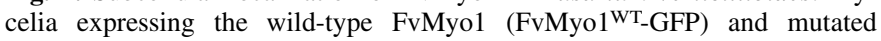

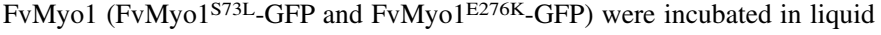
yeast extract peptone dextrose for $24 \mathrm{~h}$ and then treated with or without phenamacril $\left(2 \mu \mathrm{g} \mathrm{ml}^{-1}\right)$ for $4 \mathrm{~h}$. The boxes indicate the hyphal tip. Scale bar $=$ $10 \mu \mathrm{m} . \mathrm{DMSO}=$ dimethylsulfoxide and GFP $=$ green fluorescent protein. induced PR mutants of $F$. graminearum and $F$. oxysporum f. sp. melonis, there is no significant relationship between phenamacril resistance and fitness ( $\mathrm{Li}$ et al. 2016; Zhang et al. 2018). In field populations of PR mutants of F. fujikuroi, point mutation S219P in myosin-5 did not result in a significant fitness penalty compared with sensitive strains. However, the fitness of resistant strains conferred by the S219L mutation was less compared with sensitive strains (Hou et al. 2018). In this study, both types of UV-induced PR strains showed a decrease in biological fitness, including mycelial growth, conidiation, and virulence. However, the artificially constructed strains exhibited similar phenotypes to the WT strain. In addition to having mutations that increased resistance, PR-I and PR-II may have had other mutations that affected fungal growth and development, and point mutations (S73L and E276K) in myosin-1
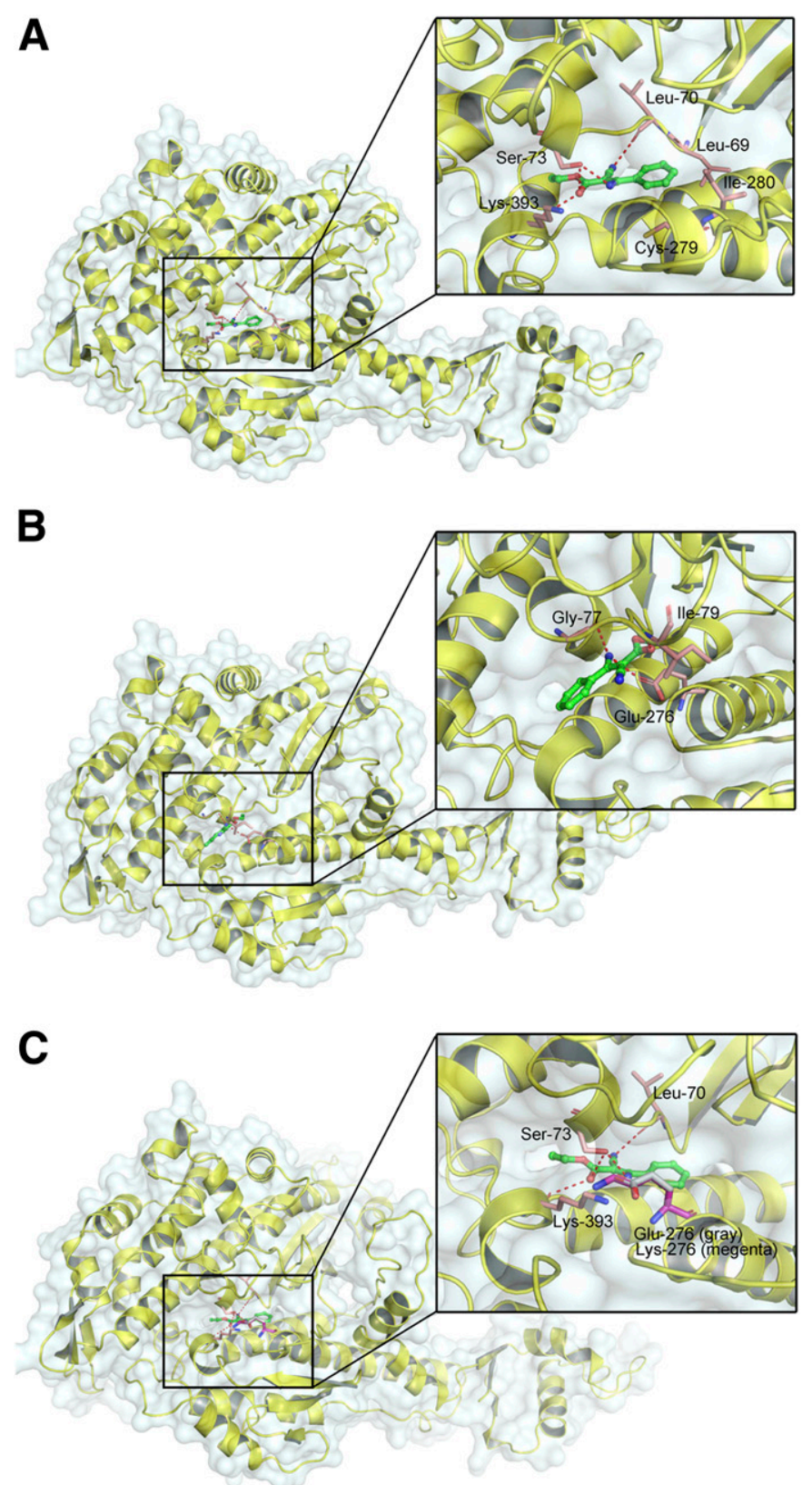

Fig. 5. Molecular docking analysis of phenamacril in the activity cavity of FvMyo1. The three-dimensional binding poses between phenamacril and $\mathbf{A}$,

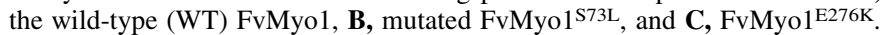
The right black box indicates the zoom-in view of the predicted binding site of FyMyo1. The key residues are shown in the stick representation and labeled by residue name and position. 
are not at the expense of fitness in F. verticillioides. We therefore suggest that the resistance risk of $F$. verticillioides to phenamacril may be moderate to high. To avoid the rapid development of resistance to phenamacril in the field, growers should reduce the number of phenamacril applications and should apply phenamacril in mixtures with multisite fungicides or with fungicides that lack cross-resistance with phenamacril.

In conclusion, single mutation S73L or E276K in myosin-1 conferred high resistance to phenamacril in $F$. verticillioides, which was not at the expense of biological fitness. The results of this study

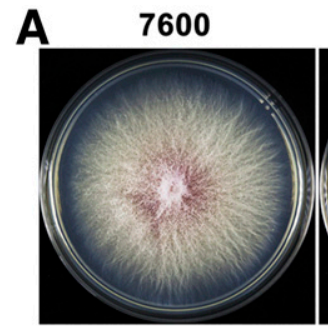

FvMyo1 ${ }^{\text {s73L }}$

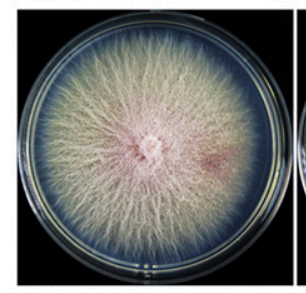

B

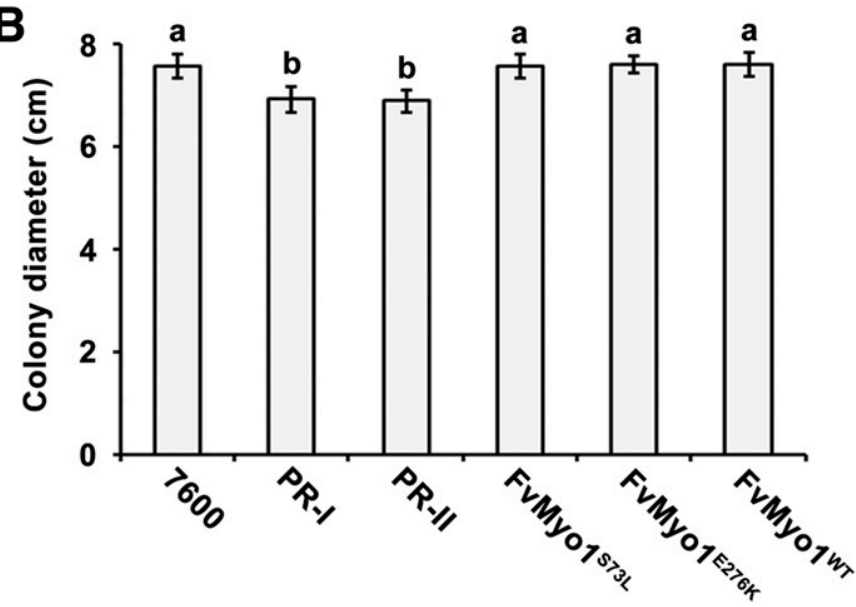

Fig. 6. Mycelial growth of Fusarium verticillioides strains. A, Colony morphology of each strain that was grown on potato dextrose agar plates for 4 days at $25^{\circ} \mathrm{C}$. B, Mycelial growth rate of each strain. Bars denote standard deviations from three experiments. Values on the bars followed by different letters are significantly different at $P=0.05$. $\mathrm{PR}=$ phenamacril resistant and $\mathrm{WT}=$ wild type.

TABLE 2. Comparison of mycelial growth, conidiation and virulence in Fusarium verticillioides strains ${ }^{\mathrm{z}}$

\begin{tabular}{|c|c|c|c|}
\hline Strain & Growth $(\mathrm{cm})$ & Conidiation $\left(\times 10^{6}\right)$ & Lesion area $\left(\mathrm{cm}^{2}\right)$ \\
\hline 7600 & $7.51 \pm 0.19 \mathrm{a}$ & $8.52 \pm 0.42 \mathrm{a}$ & $21.34 \pm 1.46 \mathrm{a}$ \\
\hline PR-I & $7.12 \pm 0.16 b$ & $7.57 \pm 0.38 b$ & $18.63 \pm 1.53 b$ \\
\hline PR-II & $7.06 \pm 0.16 b$ & $7.24 \pm 0.33 b$ & $17.18 \pm 1.48 b$ \\
\hline FvMyo1 ${ }^{\text {S73L }}$ & $7.48 \pm 0.18 \mathrm{a}$ & $8.43 \pm 0.47 \mathrm{a}$ & $21.29 \pm 1.44 \mathrm{a}$ \\
\hline FvMyo $1^{\text {E276K }}$ & $7.41 \pm 0.21 \mathrm{a}$ & $8.32 \pm 0.39 \mathrm{a}$ & $20.95 \pm 1.39 \mathrm{a}$ \\
\hline FvMyo ${ }^{\mathrm{WT}}$ & $7.56 \pm 0.24 \mathrm{a}$ & $8.65 \pm 0.41 \mathrm{a}$ & $22.03 \pm 1.47 \mathrm{a}$ \\
\hline
\end{tabular}

$\mathrm{z}$ Values are the means \pm standard deviations of three repeats. Values in a column followed by the same letters are not significantly different at $P=$ 0.05. $\mathrm{PR}=$ phenamacril resistant and $\mathrm{WT}=$ wild type. will provide a scientific basis for the registration of phenamacril for the control of maize ear rot and the subsequently rational application.

\section{LITERATURE CITED}

Ćmielová, J., and Řezáčová, M. 2011. Protein and its function based on a subcellular localization. J. Cell. Biochem. 112:3502-3506.

Fink-Grernmels, J. 1999. Mycotoxins: Their implications for human and animal health. Vet. Q. 21:115-120.

Hawkins, N. J., and Fraaije, B. A. 2018. Fitness penalties in the evolution of fungicide resistance. Annu. Rev. Phytopathol. 56:339-360.

Hou, Y. P., Qu, X. P., Mao, X. W., Kuang, J., Duan, Y. B., Song, X. S., Wang, J. X., Chen, C. J., and Zhou, M. G. 2018. Resistance mechanism of Fusarium fujikuroi to phenamacril in the field. Pest Manag. Sci. 74: 607-616.

Li, B., Zheng, Z. T., Liu, X. M., Cai, Y. Q., Mao, X. W., and Zhou, M. G. 2016. Genotypes and characteristics of phenamacril-resistant mutants in Fusarium asiaticum. Plant Dis. 100:1754-1761.

Li, H. K., Diao, Y. M., Wang, J. X., Chen, C. J., Ni, J. P., and Zhou, M. G. 2008. JS399-19, a new fungicide against wheat scab. Crop Prot. 27:90-95.

Liu, J., Taylor, D. W., Krementsova, E. B., Trybus, K. M., and Taylor, K. A. 2006. Three-dimensional structure of the myosin V inhibited state by cryoelectron tomography. Nature 442:208-211.

Ma, Z. H., and Michailides, T. J. 2005. Advances in understanding molecular mechanisms of fungicide resistance and molecular detection of resistant genotypes in phytopathogenic fungi. Crop Prot. 24:853-863.

Möller, E. M., Bahnweg, G., Sandermann, H., and Geiger, H. H. 1992. A simple and efficient protocol for isolation of high molecular weight DNA from filamentous fungi, fruit bodies, and infected plant tissues. Nucleic Acids Res. 20:6115-6116.

Morris, G. M., Huey, R., Lindstrom, W., Sanner, M. F., Belew, R. K., Goodsell, D. S., and Olson, A. J. 2009. AutoDock4 and AutoDockTools4: Automated docking with selective receptor flexibility. J. Comput. Chem. 30:2785-2791.

Munkvold, G. P. 2003. Epidemiology of Fusarium diseases and their mycotoxins in maize ears. Eur. J. Plant Pathol. 109:705-713.

Nelson, P. E., Desjardins, A. E., and Plattner, R. D. 1993. Fumonisins, mycotoxins produced by Fusarium species: Biology, chemistry, and significance. Annu. Rev. Phytopathol. 31:233-252.

Norred, W. P., and Voss, K. A. 1994. Toxicity and role of fumonisins in animal diseases and human esophageal cancer. J. Food Prot. 57:522-527.

Ranum, P., Peña-Rosas, J. P., and Garcia-Casal, M. N. 2014. Global maize production, utilization, and consumption. Ann. N. Y. Acad. Sci. 1312: 105-112.

Rheeder, J. P., Marasas, W. F. O., and Vismer, H. F. 2002. Production of fumonisin analogs by Fusarium species. Appl. Environ. Microbiol. 68: 2101-2105.

Seo, J. A., Proctor, R. H., and Plattner, R. D. 2001. Characterization of four clustered and coregulated genes associated with fumonisin biosynthesis in Fusarium verticillioides. Fungal Genet. Biol. 34:155-165.

Shim, W. B., and Woloshuk, C. P. 2001. Regulation of fumonisin B $B_{1}$ biosynthesis and conidiation in Fusarium verticillioides by a cyclin-like (Ctype) gene, FCC1. Appl. Environ. Microbiol. 67:1607-1612.

Tang, G. F., Chen, Y., Xu, J. R., Kistler, H. C., and Ma, Z. H. 2018. The fungal myosin I is essential for Fusarium toxisome formation. PLoS Pathog 14: e1006827.

Waterhouse, A., Bertoni, M., Bienert, S., Studer, G., Tauriello, G., Gumienny, R., Heer, F. T., Beer, T. A. P., Rempfer, C., Bordoli, L., Lepore, R., and Schwede, T. 2018. SWISS-MODEL: Homology modelling of protein structures and complexes. Nucleic Acids Res. 46:W296-W303.

Wilke, A. L., Bronson, C. R., Tomas, A., and Munkvold, G. P. 2007. Seed transmission of Fusarium verticillioides in maize plants grown under three different temperature regimes. Plant Dis. 91:1109-1115.

Zhang, C. Q., Chen, Y., Yin, Y. N., Ji, H. H., Shim, W. B., Hou, Y. P., Zhou, M. G., Li, X. D., and Ma, Z. H. 2015. A small molecule species specifically inhibits Fusarium myosin I. Environ. Microbiol. 17:2735-2746.

Zhang, Z. H., Ren, W. C., Wang, J., Chen, W. C., Sang, C. W., and Chen, C. J. 2018. Resistance risk assessment of Fusarium oxysporum f. sp. melonis against phenamacril, a myosin inhibitor. Pestic. Biochem. Physiol. 147: 127-132.

Zheng, Z. T., Hou, Y. P., Cai, Y. Q., Zhang, Y., Li, Y. J., and Zhou, M. G. 2015. Whole-genome sequencing reveals that mutations in myosin-5 confer resistance to the fungicide phenamacril in Fusarium graminearum. Sci. Rep. 5:8248.

Zheng, Z. T., Zhang, Y., Wu, X. Y., Yang, H., Ma, L. J., and Zhou, M. G. 2018. FoMyo5 motor domain substitutions ( $\operatorname{Val}_{151}$ to Ala and $\mathrm{Ser}_{418}$ to Thr) cause natural resistance to fungicide phenamacril in Fusarium oxysporum. Pestic. Biochem. Physiol. 147:119-126. 